\title{
Age, but Not Sex, Modulates Foxp3 Expression in the Rat Brain across Development
}

\author{
Makenzlie R. Taylor, ${ }^{a}$ Clinton R. Roby, ${ }^{a}$ Soad Elziny, ${ }^{a}$ Erin Duricy, ${ }^{a}$ Tina M. Taylor ${ }^{a}$ and J. Michael Bowers ${ }^{\text {** }}$ \\ a School of Neuroscience, 1981 Kraft Drive, ILSB, Virginia Tech, Blacksburg, VA 24061-0913, USA
}

\begin{abstract}
The interconnectivity between brain development and the immune system has become an area of interest for many neuroscientists. However, to date, a limited number of known immune mediators of the peripheral nervous system (PNS) have been found to influence the development of the central nervous system (CNS). FOXP3 is a well-established mediator of regulatory T-cells in the PNS. However, the expression pattern of FOXP3 in the CNS and the PNS throughout development is unknown. To fill this void, we have characterized, in several brain regions, the developmental profile of Foxp3 for both sexes using rats. We found different patterns of Foxp3 in the CNS and PNS. In the CNS, we found Foxp3 was ubiquitously expressed, with the levels of Foxp3 varying by brain region. We also found both Foxp3 mRNA and protein levels peak during embryonic development and then steadily decrease with a peak increase during adulthood. In adulthood, the protein but not mRNA increases to the equivalent levels found at the embryonic stage of life. In the PNS, Foxp3 protein levels were low embryonically and increased steadily over the life of the animal with maximal levels reached in adulthood. Patterns observed for both the PNS and CNS were similar in males and females across all developmental timepoints. Our novel findings have implications for understanding how the neural immune system impacts neurodevelopmental disorders such as autism and schizophrenia. (C) 2020 The Author(s). Published by Elsevier Ltd on behalf of IBRO. This is an open access article under the CC BY license (http://creativecommons.org/licenses/by/4.0/).
\end{abstract}

Key words: genes, brain development, sex differences.

\section{INTRODUCTION}

FOXP3 is a member of the Forkhead box gene family of transcription factors. There are four members of the FOXP subfamily, FOXP1-4 and denoted with human forms are capitalized (FOXP3-protein), murine forms are in lowercase (Foxp3-protein) (Kaestner et al., 2000; Sin et al., 2015). Three of the FOXP genes, FOXP1/2/4, are abundantly expressed throughout the brain (Teramitsu et al., 2004; Bowers et al., 2013), whereas FOXP3 has been recognized as being expressed primarily in the immune system (Brunkow et al., 2001; Walecki et al., 2015). Numerous studies have focused on understanding the function of FOXP1/2/4, due to their well-established link to brain development, autism, and language impairment (Lai et al., 2001; Vernes et al., 2008; Girirajan et al., 2011; Bacon and Rappold, 2012; Bowers and Konopka, 2012; Rappold et al., 2017). In contrast, FOXP3 has been regarded as an immune system regulator being expressed in the peripheral nervous system (PNS) with low expression in the brain (Takahashi et al., 2009;

\footnotetext{
*Corresponding author.

E-mail address: bmike1@vt.edu (J. M. Bowers).

Abbreviations: ASD, autism spectrum disorder; IPEX, immunodysregulation, polyendocrinopathy, enteropathy, X-linked disorder; PNS, peripheral nervous system; qRT-PCR, Quantitative real-time PCR; Treg, regulatory T-cells.
}

Mailer, 2018). It is also known that FOXP3 is the only member of the FOXP subfamily that is located on a sex chromosome, specifically the $X$ chromosome (Lu et al., 2017). Additionally, FOXP3 impacts immune system functions by its key role in the development and function of regulatory T-cells (Treg) (Fontenot et al., 2003, 2005; Hori et al., 2003). In humans, FOXP3 is present in two isoforms, one of which is encoded by a complete mRNA, and the other by a truncated variant that lacks exon 2 (Walker et al., 2003; Allan et al., 2005; Du et al., 2008). The expression levels of these two isoforms appears to be equivalent in Treg cells (Du et al., 2008). Previous findings show that the truncated variant of FOXP3 lacks the DNA binding domain, which results in an autoimmune disorder in humans called IPEX, (immunodysregulation, polyendocrinopathy, enteropathy, X-linked disorder), and in mice this truncation results in scurfy (Deng et al., 2012). FOXP3 has also been found to be expressed in fetal and adult human brains (Frattini et al., 2012), and in the adult hippocampus of mice (Yi et al., 2016), but no information is known about Foxp3 in the rat brain.

We propose that investigating the role of Foxp3 in the brain can provide insights into how mediators of the PNS immune are connected with and influence the development of the central nervous system (CNS). There already exists a strong connection for how 
dysregulations of the immune system contribute to brain development through the occurrence of disorders in the brain. For instance, irregular immune system functioning is often comorbid with neurodevelopmental disorders (e.g., schizophrenia and Rett syndrome) (Patterson, 2009; Zhao et al., 2017; Gottfried and Bambini-Junior, 2018; Benros and Mortensen, 2019), as well as neuropsychiatric disorders (e.g., depression and anxiety) (Khandaker et al., 2014; Rainville et al., 2018). Likewise, immune system disorders are over-represented in the population of individuals with autism or autism spectrum disorder (ASD) (Kohane et al., 2012; Bauman et al., 2013; Rossi et al., 2013; Brimberg et al., 2016).

In the present research, we considered several important characteristics such as age of animal, the specific brain region of expression, and sex. For instance, FOXP1, FOXP2, and FOXP4 are known to be expressed together in neural tissue and play an important role in the initial stages of neurodevelopment (Bowers and Konopka, 2012; Bowers et al., 2014). Moreover, Foxp1 and Foxp2 mRNA and protein levels have been shown to vary across the lifespan (Dallaire et al., 2003; Campbell et al., 2009; Bowers et al., 2014). In addition, FOXP1/2/4 are each known to be either expressed separately in a specific brain region or to be coexpressed in the same cell, which is also dependent on the specific region of the brain (Ferland et al., 2003; Takahashi et al., 2008; Campbell et al., 2009; Tam et al., 2011; Bowers et al., 2014; Fong et al., 2018). It has also been shown that mRNA and protein levels for Foxp1 and Foxp2 are expressed differently in males and females in some, but not all, regions of the brain (Bowers et al., 2013, 2014; Frohlich et al., 2017). These sex differences in the brain, for both Foxp1 and Foxp2, have been linked to sex differences in neonatal ultrasonic vocalizations (Bowers et al., 2013; Frohlich et al., 2017). Androgens have also been found to regulate both Foxp2 and Foxp1 protein levels differentially in males versus females (Bowers et al., 2014; Frohlich et al., 2017). These data strongly suggest age, brain region, and sex are relevant factors potentially mediating Foxp $1 / 2 / 4$ expression in the brain. It is not known whether Foxp3 shares these distinctive features in the brain like the other Foxp family members.

We aimed to measure the expression of Foxp3 in the CNS and the PNS across development for both male and female rats. We quantified the mRNA and protein levels for Foxp3 assaying tissue from across the lifespan (i.e., from embryonic to adulthood), and from different brain regions from both males and females, as well as from the spleen. The results showed that in both the CNS and the PNS, expression of Foxp3 protein and mRNA varied across development. Furthermore, we found there were different patterns of expression of Foxp3 in the CNS and the PNS. In the CNS, we found Foxp3 mRNA and protein levels in the brain are at peak levels during embryonic development and decreased across the lifespan until adulthood. At adulthood, there was an increase in Foxp3 to the equivalent levels found during embryonic development. Secondly, we found Foxp3 did not have the same expression profile across the brain (i.e., Neocortex, striatum, hippocampus). Each brain region had a unique expression pattern across the lifespan. In tissue from the spleen, which we are using as a proxy for the PNS levels, we found that Foxp3 protein levels in the PNS were found to have low levels of protein during the embryonic stage and steadily increase over the lifespan into adulthood. Additionally, we found overall Foxp3 protein levels were higher in the spleen than in the brain. The low levels of Foxp3 in the brain may be a reason why Foxp3 has not been reported to be measured in the brain for a number of publications investigating the Foxp genes (Lu et al., 2002; Li et al., 2004; Mendoza et al., 2015; Sin et al., 2015; Mendoza and Scharff, 2017). For both the CNS and PNS, patterns of results were similar for males and females with no sex differences in Foxp3.

\section{EXPERIMENTAL PROCEDURES}

Brain and spleen tissue from animals were dissected at several timepoints. We collected tissue before birth (embryonic, E) and after birth (postnatal, PN) at the following ages: E19, PN0, PN7, PN14, PN21, PN28, PN48 and PN65 for quantitative real-time PCR (qRT$P C R$ ) and Western blot analysis. Five different litters were used to obtain embryonic tissue. Twelve different litters were used to obtained postnatal brain tissue. All timepoints had a comparable number of males and females. The pups from each litter were randomly assigned to a specific timepoint in order to distribute pups from any one litter across all timepoints. The total number of animals used for the qRT-PCR $=$ (timepoint $\# 1 n=20$ and timepoint $\# 2 n=42)$ and Western blot $=$ (timepoint $\# 1 n=34$, timepoint $\# 2 n=52$, timepoint $\# 3 n=51)$. The breakdown of male and females per age are noted in the figure legends with each data result. Brain dissections were conducted for: neocortex, hippocampus, and striatum. Dissections were performed using a rat coronal section brain block that had $1.0 \mathrm{~mm}$ interval divisions (Stoelting). The individual brain regions were obtained from serial sections using coronal slices going from anterior to posterior regions throughout the entire brain. For the GRT-PCR analysis, the analysis was divided into Timepoint 1: E19, PN0, PN7 and Timepoint 2: PN0, PN7, PN14, PN21, PN28, PN48, PN65. Due to size limitations of the Western blot membrane, the timepoints across the lifespan were separated as follows: Timepoint 1: E19, PNO, PN7; Timepoint 2: PN0, PN7, PN14, PN21; and Timepoint 3: PN21, PN28, PN48, PN65. This division of qRT-PCR analysis into two separate time points and the Western blot into three timepoints was due to the high number of individual samples being processed. It was impossible for use to put all our samples in one PCR plate, or in one Western blot membrane. We also choose to overlap one to two timepoints for GRT-PCR and Western blot in order to serve as an internal comparison. The internal comparisons served as a proxy for us to qualitatively determine any runtime changes between qRT-PCR plates or Western blot membrane processing. Spleen tissue was used as a 
proxy for the peripheral immune tissue levels and was collected at the same timepoints and from the same animals we obtained the brain tissue.

\begin{abstract}
Animals
Long Evans rats were mated and raised in our vivarium under a 12-h dark and 12-h reverse light cycle. Females were allowed to deliver naturally. The day of birth was designated as PNO. All animals were housed in polycarbonate cages $(20 \times 40 \times 20 \mathrm{~cm})$ in corncob bedding with water and food ad libitum. Virginia Tech Institutional Animal Care and Use Committee approved all animal procedures.
\end{abstract}

\section{qRT-PCR}

RNA was prepared from frozen rat brain tissue samples using Qiazol and purified on RNeasy columns (Qiagen) with DNase digestion. Using $1 \mu \mathrm{g}$ of tissue, RNA was transcribed to CDNA using the Transcriptor first-strand cDNA Synthesis Kit (Roche Applied Science) using both anchored-dT and random primers. A quantity of $1.2-3.0 \mathrm{mg}$ was used in a reaction to synthesize cDND. qRT-PCR was performed on a QuantStudio-6 Flex (Applied Biosystems) with Quant Studio Real-Time PCR software. qRT-PCR was performed with an annealing temperature of $60^{\circ} \mathrm{C}$, using Power SYBR Green master mix (Applied Biosystems). Specific primers for the gene Foxp3 and the control normalizing genes Rp/13a and Tata Binding Protein, (TBP) were designed using Primer Express 3.0. Primers for Foxp3 gene followed the sequence: forward, 5'-TTTATGCATCAGCTCTCCACTG TAG-3', and reverse, 5'-GAGAAGACTCCAGTGGCAG CAGTA-3'. For sexing of embryonic tissue, we used primers targeting the Sry gene 5'-GCGCCCCATGAATG CAT-3' and reverse, 5'-TGGGATTCTGTTGAGC CAACT-3'. The primers specific for Sry were obtained from a previously published manuscript (Turner et al., 2007) and used by us in a previous publication (Bowers et al., 2013). Primers for the first housekeeping gene Rp/13a gene followed the sequence: forward, $5^{\prime}$-AGG CAAAGATCCATTACCGG-3', and reverse, 5'-GGCA CAAACAGTCTTTATTGGG-3'. Primers for the second housekeeping gene TBP gene followed the sequence: forward, 5'-ACCGAAGAAAGTGAGAGTCATGGA-3', and reverse, 5'-CGTAAGGCATCATTGGACTGAAGA-3'. Data were analyzed using the standard curve method. This method is used as a standard or calibration curve for extrapolating relative expression level information for the gene of interest in unknown experimental samples. The relative quantification calibration curve results for the gene of interest is normalized to that of a control normalizing gene in the same samples, and then the normalized numbers are compared between samples to get a fold change in expression. We compared the two normalizing genes and found they were not statistically different from each other at any timepoint. We cross-compared the two normalizing genes to further confirm the expression pattern of Foxp3, but only report one, Rp/13A, in order to be succinct.

\section{Western blot}

Animals were euthanized either by rapid decapitation (<PN4) or using deep anesthesia (>PN5) to dissect and process brain tissue as previously reported (Bowers et al., 2014). Twenty-five micrograms of protein were electrophoresed in separate lanes using 4-20\% TrisGlycine polyacrylamide gels (Invitrogen Novex) and transferred to a low fluorescence PVDF membrane (Bio-Rad). Membranes were blocked in Odyssey blocking buffer (LICOR) for 1-h and then incubated with the monoclonal anti-mouse Foxp3 antibody (1:1000; Santa Cruz) overnight at $4{ }^{\circ} \mathrm{C}$. This Foxp3 primary antibody has been used in previous published work (Fu et al., 2019; Shu et al., 2019). After 1-h of incubation with the corresponding fluorescent secondary, antibody anti-mouse (IRDye 680 RD, LI-COR (1: 15,000; LI-COR), the immunoreactive bands were detected and digitalized using the Odyssey Fc Imaging System (LI-COR). Total protein stain was used for normalization of the Western blots. The Foxp3 protein was detected as a band with a relative molecular weight of $\sim 49 \mathrm{kDa}$. For relative quantification purposes, the band for the protein of interest was divided by the total protein and is expressed as "Normalized Optical Intensity" in arbitrary units.

\section{Statistical analysis}

All data are expressed as mean \pm SEM and effect size estimate calculations $\left(\eta^{2}\right.$ and $\left.r^{2}\right)$ are reported. All datasets were first tested for normality using Levene's test for homogeneity of distribution (Levene, 1960). Homogeneity analysis found our distributions to be normally distributed. Thus, we analyzed our data using a parametric two-way ANOVA with age and sex as main factors, after we determined that litter was not a significant contributing factor by using litter as an additional covariate factor of analysis. All statistical analyses were followed by a post hoc pairwise comparison test. To control for familywise error for multiple pairwise comparisons, we used the Holm's sequential Bonferroni correction. Any pairwise comparisons not following this criterion were considered statistically non-significant. All statistical tests were computed in SPSS 26 and graphed using GraphPad Prism 8.2.1.

\section{RESULTS}

\section{Foxp3 mRNA analysis by qRT-PCR}

Whole brains were collected on E19, and for the postnatal timepoints we separated into the neocortex, striatum, hippocampus. Because the embryonic brain is not well differentiated at E19, we compared only these three brain regions.

\section{Timepoint 1: mRNA expression during embryonic and early postnatal points}

Neocortex. We found a significant main effect for age, $F$ $(2,17)=19.071, p<0.000, \eta^{2}=0.692$. However, the main effect for sex was not statistically significant, $F<1.0$. Pairwise comparisons found Foxp3 mRNA 
levels were higher at E19 when compared to PNO and PN7, $t(12)=3.059, p=0.010, r^{2}=0.66192$ and $t$ $(12)=8.912, \quad p<0.000, \quad r^{2}=0.93206, \quad$ respectively
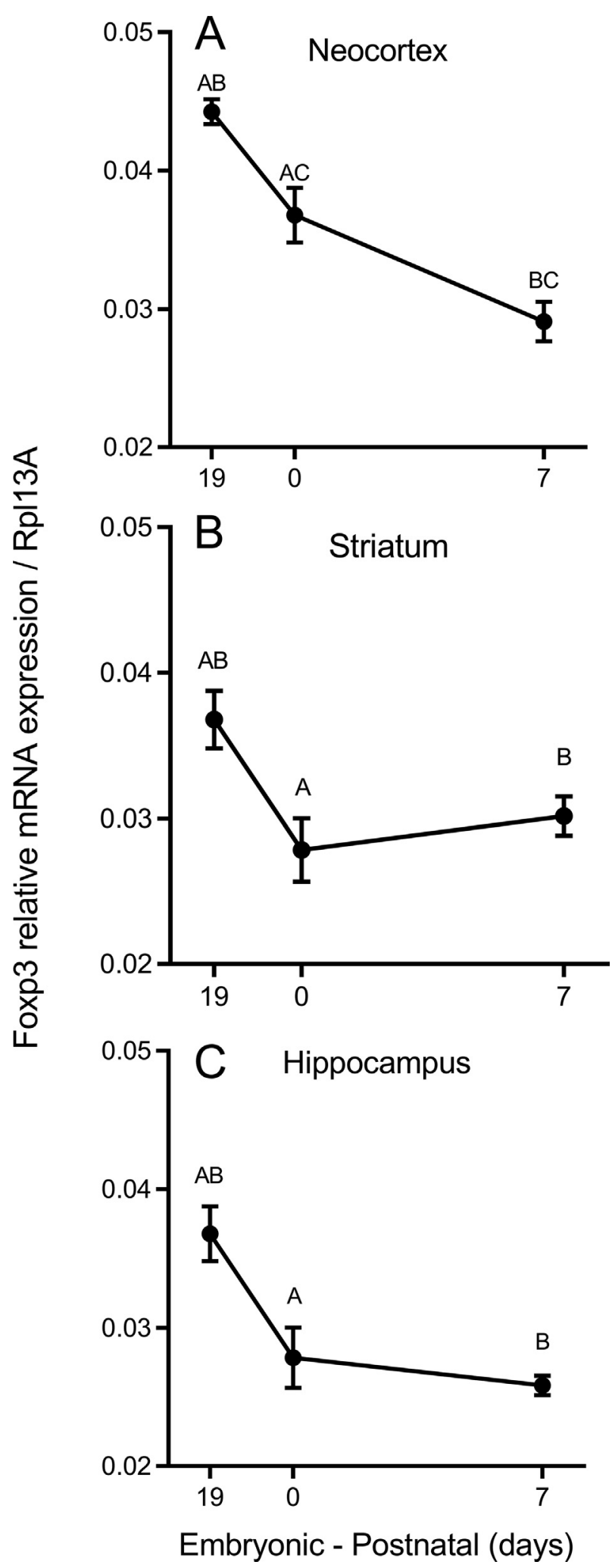

(Fig. 1A). Additionally, PN0 was found to have significantly higher levels of Foxp3 mRNA than PN7, $t$ $(10)=2.935, p=0.012, r^{2}=0.68028$.

Striatum. Levels of Foxp3 mRNA showed a significant main effect for age, $F(2,17)=6.229, p=0.009$, $\eta^{2}=0.423$, but not sex, $F<1.0$. Pairwise comparisons found Foxp3 mRNA levels were higher at E19 when compared to both PNO and PN7, $t(12)=3.008$, $p=0.011, r^{2}=0.65565$ and $t(12)=2.554, p=0.025$, $r^{2}=0.59343$, respectively (Fig. 1B). PN0 and PN7 were not statistically different from each other, $t(10)=0.909$, $p=0.385$.

Hippocampus. Levels of Foxp3 mRNA showed significant differences of age, $F(2,17)=10.925$, $p=0.001, \eta^{2}=0.562$, but not sex, $F<1.0$. Pairwise comparisons found Foxp3 mRNA levels were higher at E19 when compared to both PN0 and PN7, $t$ (12) $=3.010, p=0.011, r^{2}=0.6559$ and $t(12)=4.570$, $p=0.001, r^{2}=0.79693$, respectively (Fig. 1C). PN0 and PN7 were not statistically different from each other, $t(10)=0.872, p=0.403$.

\section{Period 2: Postnatal timeline from P0 to P65}

Neocortex. The mRNA levels of Foxp3 were statistically significant for the main effect of age, $F(6,33)=7.534$, $p<0.000, \quad \eta^{2}=0.578$. However, there was no significant main effect for sex, $F<1.0$. Pairwise comparisons found Foxp3 mRNA was significantly higher at PN0 as compared to PN7 and PN14, $t$ (10) $=5.160, p<0.000, r^{2}=0.85262$ and $t(10)=4.194$, $p=0.002, r^{2}=0.79846$, respectively (Fig. 2A). After correcting for multiple pairwise comparisons, there were no additional significant differences.

Striatum. There was no significant main effect for age, $F(6,33)<1.0$, or for sex found, $F<1.0$ (Fig. 2B).

Hippocampus. There was a significant main effect for age, $F(6,33)=5.661, p<0.000, \eta^{2}=0.507$, but no main effect for sex was found, $F<1.0$. Pairwise comparisons found higher Foxp3 expression at PN21 when compared to PN7 and PN14, $t(10)=4.641$, $p=0.001, r^{2}=0.8264$ and $t(10)=4.853, p=0.001$, $r^{2}=0.83783$ respectively (Fig. 2C).

\section{Foxp3 protein measurements by Western blot}

We collected brain tissue from the neocortex, striatum, and hippocampus at the same time points as reported

Fig. 1. (A-C) Relative expression of Foxp3 mRNA in the rat brain. Timepoint 1 (E19: 우 $=4, \hat{\jmath}=4$; PN0: 우 $=3, \hat{\jmath}=3$; PN7: 우 $=3$, $\hat{\sigma}=3$ ) late embryonic and early postnatal development in the neocortex (A), striatum (B), and hippocampus (C). All data are expressed as mean $( \pm$ SEM). Groups with the same alphabetic script are significantly different from each other. A group with more than two alphabetic scripts indicates that the individual group is significantly different from more than one group, e.g. "AB" listing over one group would denote that the group is different from any group with an " $A$ " and is also significantly different from any group with a "B". 
for qRT-PCR (i.e., E19, PN0, PN7, PN14, PN21, PN28, PN48, PN65). To test the efficacy of the primary antibody, we compared the molecular weight from a tissue sample known to have high levels of Foxp3

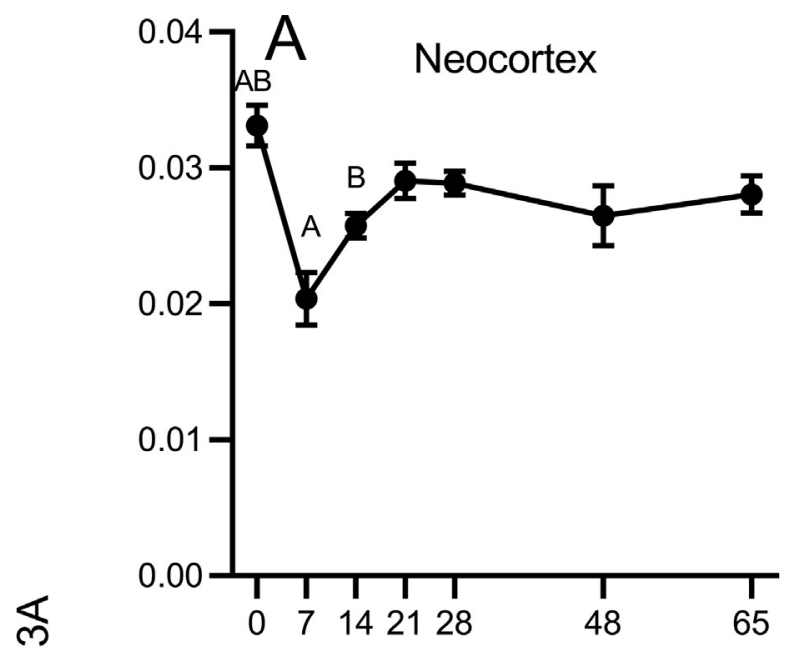

protein, the spleen, to the three brain regions we quantified (Eufrasio de Figueiredo et al., 2019). The observed molecular weight in the spleen was identical to the protein levels from the brain, (Fig. 3A). We also noted that the molecular weight for Foxp3 did not change in the brain across the lifespan, (Fig. 3B).

\section{Timepoint 1. Embryonic and early postnatal period}

Neocortex: The analysis showed a significant main effect of age for Foxp3, $F(2,27)=17.807, p<0.001$, $\eta^{2}=0.569$, but not sex, $F<1.0$. In the neocortex, basal levels of Foxp3 protein were higher at E19 when compared to PN0, $t \quad(18)=3.052, \quad p=0.007$, $r^{2}=0.58396$ and PN7, $t(18)=6.804, p<0.001$, $r^{2}=0.84855$. Moreover, the protein levels were significantly higher when comparing PN0 to PN7, $t$ (24) $=3.984, p=0.001, r^{2}=0.63093$, (Fig. 4A).

Striatum: Foxp3 protein levels were statistically significant for the main effect of age, $F(2,29)=8.625$, $p=0.001, \eta^{2}=0.373$, but not sex, $F<1.0$. Pairwise comparisons found Foxp3 protein levels where higher at E19 than at PN0, $t(19)=4.026, p=0.001$, $r^{2}=0.6785$. Likewise, Foxp3 protein was higher at E19 than at PN7, $t(16)=2.346, p=0.032, r^{2}=0.50591$ (Fig. 4B). However, after correcting for multiple pairwise comparisons, there were no statistically significant differences in protein levels between PN0 and PN7, $t$ $(23)=-2.086, p=0.048$.

Hippocampus: Foxp3 protein levels were statistically significant for the main effect of age, $F(2,28)$ $=13.897, p<0.000, \eta^{2}=0.498$, but not the main effect of sex, $F<1.0$. Pairwise comparisons found significant higher levels of Foxp3 protein levels at E19 when comparing this age to PNO and PN7, $t$ (16) $=2.864, p=0.011, r^{2}=0.58216$ and, $t(18)=6.730$, $p<0.000, r^{2}=0.84594$, respectively. Foxp3 protein levels were not statistically different when comparing PN0 to PN7, $t(22)=2.043, p=0.053$, (Fig. 4C).

\section{Timepoint 2. First postnatal weeks of development}

Four timepoints consisting of day of birth and weaning were assayed for this timepoint, (i.e., PN0, PN7, PN14, $P N 21)$. For the neocortex, there was a significant main effect of age for Foxp3 protein levels, $F(3,44)=4.032$, $p=0.013, \eta^{2}=0.216$, but not for the main effect of sex, $F<1.0$. Pairwise comparisons found significant higher levels of Foxp3 protein levels at PNO when

Fig. 2. (A-C) Relative expression of Foxp3 mRNA from birth to adulthood. Timepoint 2 (PN0: $\circ=0=3, \hat{o}=3$; PN7: $\circ=3, \hat{o}=3$; PN14: $q=3, \hat{o}=3 ;$ PN21: $q=3, \hat{o}=3$; PN28: $q=3, \hat{o}=3$; PN48: $ᄋ=3, \hat{o}=3$; PN65: $q=3, \hat{o}=3$ ), early postnatal development to adulthood: neocortex (A), striatum (B), and hippocampus (C). All data are expressed as mean ( \pm SEM). Groups with the same symbol are significantly different from each other. A group with more than two alphabetic scripts indicates that the individual group is significantly different from more than one group, e.g. "AB" listing over one group would denote that the group is different from any group with an " $A$ " and is also significantly different from any group with a "B". 

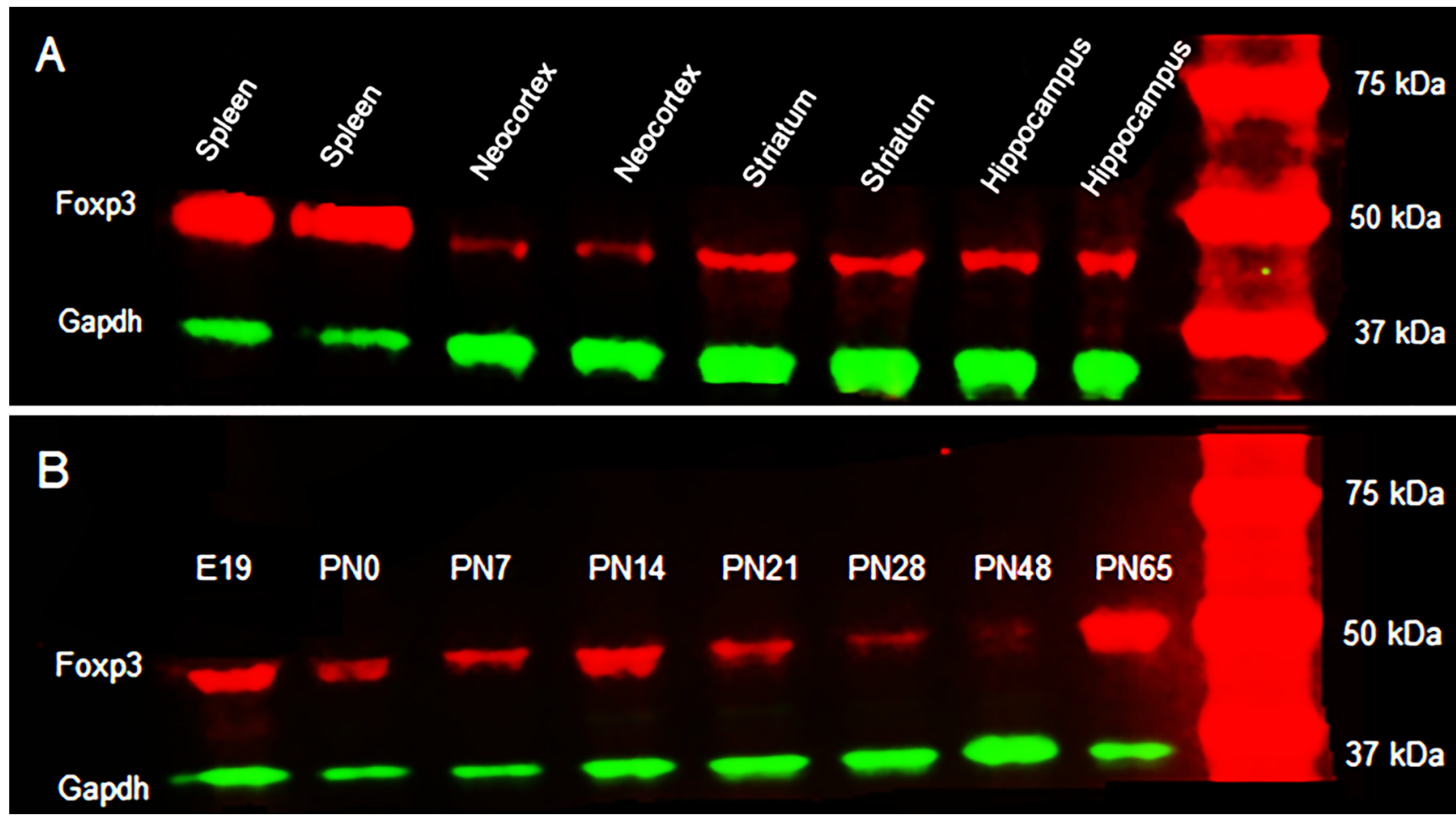

Fig. 3. (A, B) Foxp3 identification and protein assessment in the rat brain. (A) Detection of Foxp3 ( $49 \mathrm{kDa}$ ) by western blot in the spleen, neocortex, striatum, and hippocampus. (B) A representation of Foxp3 developmental profile from embryonic stages to adulthood.

compared to PN7, $t \quad(24)=5.862, \quad p<0.000$, $r^{2}=0.76732$ and also when comparing PN0 to PN14, $t$ $(24)=2.531, p=0.018, r^{2}=0.459$. No other pairwise comparisons were significant, (Fig. 5A).

Striatum. The analysis did not show any significant differences in Foxp3 protein levels for the main effect of age or sex during this period from PN0-PN21, Fs $<1.0$, (Fig. 5B).

Hippocampus. A significant main effect for age was found, $F(3,44)=4.545, p=0.007, \eta^{2}=0.237$, but not for the main effect of sex, $F<1.0$. Pairwise comparisons found no differences between PNO and PN7, $t(20)=0.414, p=0.683$. However, significant increases in Foxp3 protein were found when comparing PN0 to PN14, $t \quad(20)=-2.519, \quad p=0.020$, $r^{2}=0.49077$, and PN0 to PN21, $t(20)=-2.451$, $p=0.024, r^{2}=0.48061$, (Fig. 5C).

\section{Timepoint 3. Juvenile and adulthood stages}

Four ages were assayed for this timepoint, (i.e., PN21, PN28, PN48, PN65). For the neocortex, there was a significant main effect of age, $F(3,43)=10.595$, $p<0.000, \eta^{2}=0.419$, but no significant main effect or sex was found, $F<1.0$. Pairwise comparisons found significant decreases in protein levels when comparing PN21 to PN28, $t(25)=3.828, p=0.001, r^{2}=0.6079$ and PN21 to PN48, $t(25)=4.103, p<0.000$, $r^{2}=0.63436$, but not between PN21 and PN65, $t(22)$ $=0.012, p=0.991$. A significant increase in Foxp3 protein was found comparing PN28 to PN65, $t$ (23) $=-3.007, p=0.006, r^{2}=0.53122$, and PN48 to
PN65, $\quad t \quad(23)=-3.218, \quad p=0.004, \quad r^{2}=0.55719$ (Fig. 6A).

Striatum. A main effect for age was found, $F(3,41)$ $=10.078, p<0.000, \eta^{2}=0.424$, but no main effect for sex was detected during this period $F<1.0$. Pairwise analyses found a significant decrease in Foxp3 protein levels at PN28 when compared with PN48, $t$ (18) $=5.480, p<0.000, r^{2}=0.79072$, but no significant differences at any other timepoints were found (Fig. 6B).

Hippocampus. A significant main effect of age for was found, $F(3,44)=10.595, p<0.000, \eta^{2}=0.419$, but not for the main effect of sex, $F<1.0$. Pairwise comparisons found Foxp3 protein levels decreased when comparing PN21 to PN28 and PN48, $t$ (25) $=3.316, p=0.003, r^{2}=0.5527$ and $t(25)=3.633$, $p=0.001, \quad r^{2}=0.58782, \quad$ respectively. In contrast, Foxp3 protein levels were found to increase when comparing PN28 and PN48 to PN65, $t(23)=-3.621$, $p=0.001, \quad r^{2}=0.60257, \quad$ and $t \quad(23)=-4.021$, $p=0.001, r^{2}=0.64249$, respectively. Protein levels were not significantly different comparing PN21 to PN65, $t(23)<0.300, p>0.05$, (Fig. 6C).

\section{Foxp3 across the lifespan in the PNS}

We analyzed Foxp3 protein levels in the spleen across the lifespan as an estimate for the protein levels of Foxp3 circulating in the PNS. We found a significant main effect of age, but not sex, $F(7,23)=12.564$, $p<0.000, \quad \eta^{2}=0.793$ and $(F<1.0, \quad p>0.05)$ respectively. Foxp3 protein levels significantly increased at each timepoint when comparing E19 to PNO, 
$t(6)=-2.625, p=0.03, r^{2}=0.73113, E 19$ to PN7, $t(6)=-6.075, p=0.001, r^{2}=0.92745, \mathrm{E} 19$ to PN14,
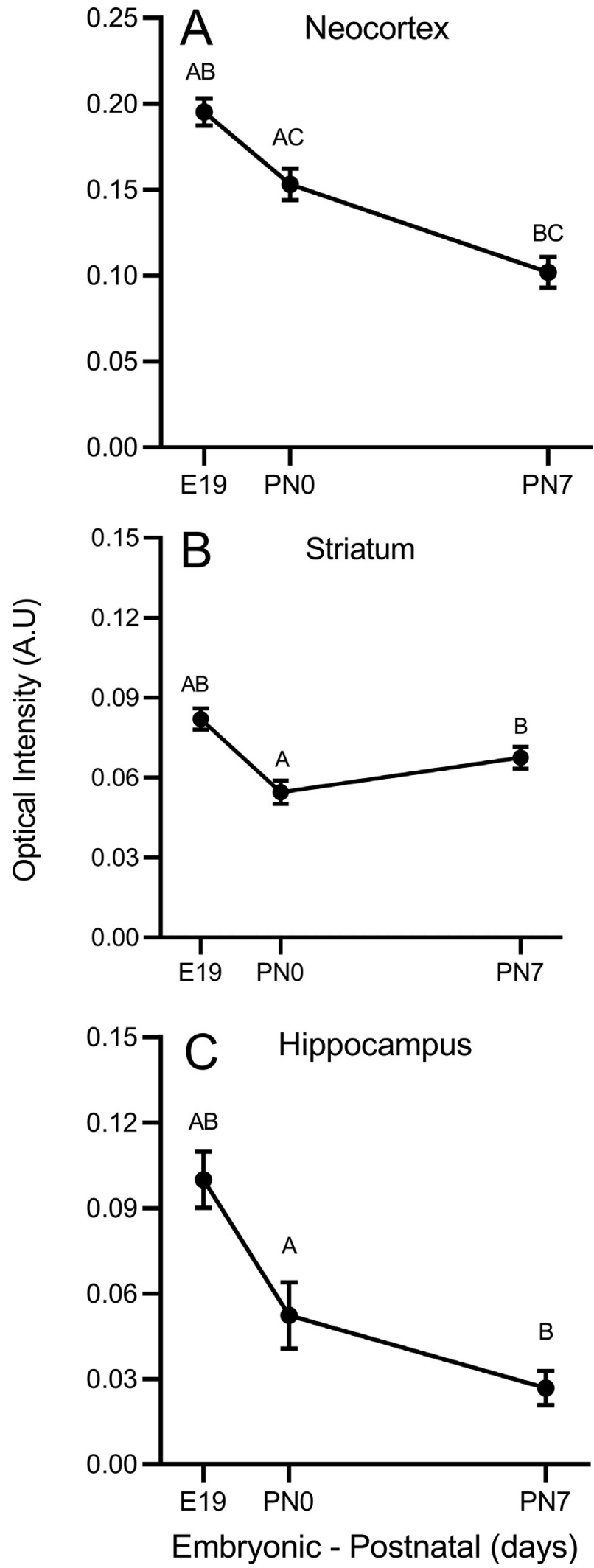

$t(6)=-4.849, p=0.003, r^{2}=0.89258, \mathrm{E} 19$ to PN21, $t(6)=-4.125, p=0.006, r^{2}=0.85983, \mathrm{E} 19$ to $\mathrm{PN} 28$, $t(6)=2.482, p=0.049, r^{2}=0.71175$, and $\mathrm{E} 19$ to PN65, $t(6)=-5.550, p=0.003, r^{2}=0.91486$. When correcting for multiple pairwise comparisons, there were no statistically significant findings for E19 to PN48, $t(6)=-0.0 .136, p=0.896$, (Fig. 7).

\section{Comparing embryonic and adulthood timepoints for Foxp3 in brain and spleen tissue}

In order to directly compare embryonic and adult tissue, from the periphery (i.e., spleen) and the brain, we quantified both the mRNA and protein level for Foxp3. For the mRNA, there was a significant interaction between tissue type (i.e., brain vs. spleen) and age (i.e., E19 vs. PN65), $F(1,8)=45.046, p<0.000$, $\eta^{2}=0.849$. Pairwise comparisons for the E19 timepoints showed that there were significantly higher levels of Foxp3 mRNA in the brain than in the spleen, $t$ (4) $=9.311, p=0.001, r^{2}=0.9777$. In contrast, there was no significant difference in Foxp3 mRNA levels comparing E19 fetal brain to PN65 adult brain, $t$ (4) $=1.195, p=0.298$. However, comparing E19 spleens to PN65 spleens, there was a significant increase in Foxp3 mRNA levels, $t \quad(4)=6.848, \quad p=0.002$, $r^{2}=0.9599$. Lastly, Foxp3 mRNA levels were significantly higher in the PN65 spleen as compared to the PN65 brain, $t(4)=6.171, p=0.004, r^{2}=0.95129$, (Fig. 8A).

For the protein, there was a significant interaction between tissue type (i.e., brain vs. spleen) and age (i.e., E19 vs. PN65), $F(1,13)=23.667, p<0.000$, $\eta^{2}=0.645$. Pairwise comparisons for the E19 timepoints showed that there were significantly higher levels of Foxp3 protein in the spleen than in the brain, $t$ $(7)=5.792, p=0.001, r^{2}=0.90959$. In contrast, there was no significant difference in Foxp3 protein levels comparing E19 brain and PN65 brain, $t(8)=-1.706$, $p=0.126$. However, comparing E19 spleens to PN65 spleens, there was a significant increase in Foxp3 protein levels, $t(6)=-4.906, p=0.004, r^{2}=0.89468$. Lastly, Foxp3 protein levels were significantly higher in the PN65 spleen as compared to the PN65 brain, $t(7)=6.340, p=0.001, r^{2}=0.92287$, (Fig. 8B).

\section{DISCUSSION}

The ability for the immune system to influence the peripheral and central nervous system is an area of special interest in understanding neurodevelopmental

Fig. 4. (A-C) Foxp3 protein quantification around the perinatal period. (E19: $q=4, \hat{\jmath}=4$; PN0: $q=7, \hat{\jmath}=6$; PN7: $q=7$, $\hat{o}=6$ ) in the neocortex (A), striatum (B), and hippocampus (C). All data are expressed as mean ( \pm SEM). Groups with the same symbol are significantly different from each other. A group with more than two alphabetic scripts indicates that the individual group is significantly different from more than one group, e.g. "AB" listing over one group would denote that the group is different from any group with an " $A$ " and is also significantly different from any group with a "B". 
disorders. This is because of the increasing information for how the immune system of the brain shapes neural development. A perfect example is the neurodevelopmental disorder, ASD. Individuals with
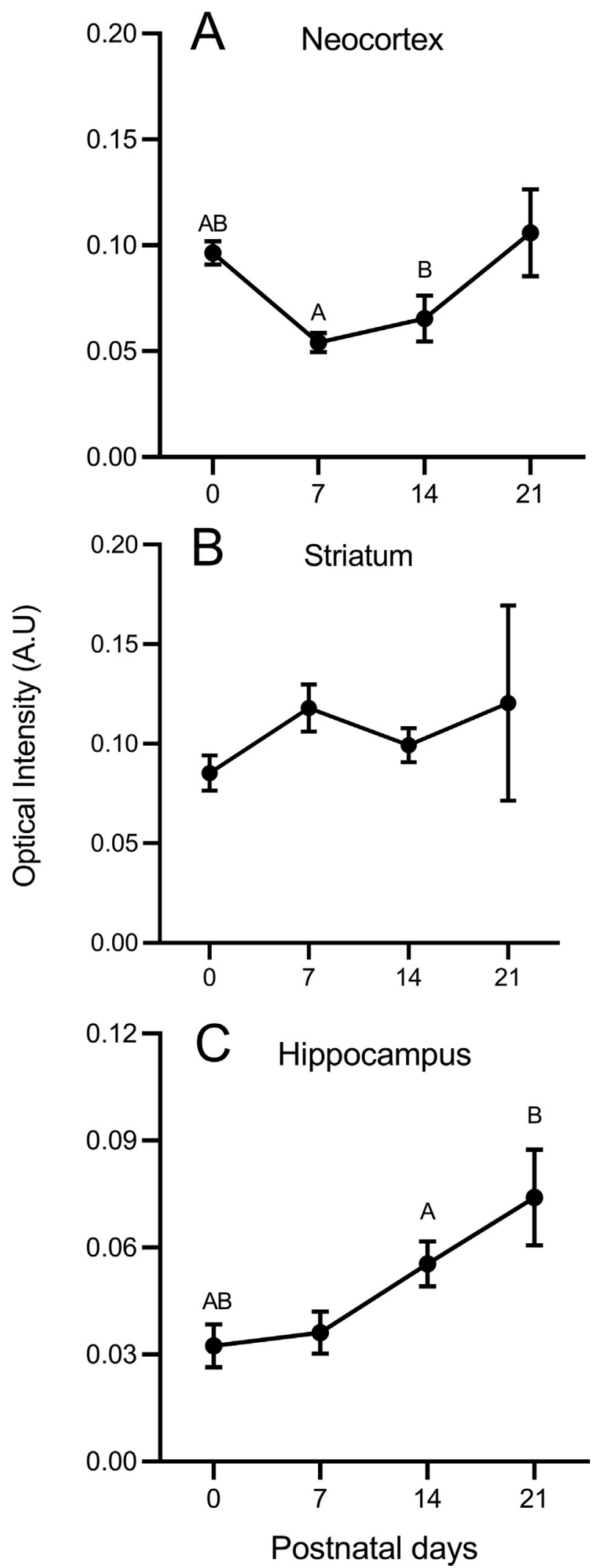

ASD are reliably diagnosed by 24 months of age (Lord et al., 2006). This is a period of extensive neuronal development, including dendritic and synaptic spine growth and refinement (Rakic et al., 1986; Greenough et al., 1987; McGee et al., 2014). As dendrites are the main structures that receive information in neurons, the complexity of dendrites and synaptic spine numbers impact neuronal connectivity and communication (Vanleeuwen and Penzes, 2012; Raven et al., 2018). Development, refinement, and maintenance of the neuronal dendritic arbors are therefore crucial to normal brain function. The reported function of FOXP 1/2/4 is to shape neural development (Bowers and Konopka, 2012). Thus, FOXP 1/2/4 have been the focus of intense neural research, whereas the fourth member of the FOXP family, FOXP3, has not received this same attention. What is known about FOXP3 suggests it is a regulator of the peripheral immune system (Haque et al., 2011; Ohkura et al., 2013). We are aware of one publication that has investigated FOXP3 expression in the human brain (Frattini et al., 2012). What is known suggests that during human fetal development, FOXP3 expression is found in the periventricular zone and cortical areas (Frattini et al., 2012). In the adult human brain, FOXP3 expression has been detected throughout the brain (Frattini et al., 2012). In mice, Foxp3 was found in the adult hippocampus (Yi et al., 2016).

A gap in our understanding of FOXP3 is why has this transcription factor not been studied in the brain, as has been the other members of the FOXP family? We speculated this was due to the low expression levels of FOXP3 in the brain, relative to the other FOXP members. Subsequently, we know nothing about expression profile of FOXP3 across the lifespan in either the periphery or brain. Thus, to better understand the expression profile across the lifespan, we assayed several areas of the rat brain (i.e., neocortex, striatum, and hippocampus) and the spleen at various time points ranging from embryonic development to adulthood (i.e., E19, PN0, PN7, PN14, PN21, PN28, PN48 and PN65).

The qRT-PCR and Western blot analyses found an overall trend for Foxp3 to have its highest expression in the brain for both mRNA and protein at E19 and the decrease throughout timepoint 1 (i.e., the first postnatal week) in all brain regions. This first week in the development of the rat is analogous to the third trimester of the developing human fetus (Patten et al., 2014; Zamudio-Bulcock et al., 2014). In rats, E1-E10 is the equivalent to the first trimester in humans with E10E20 (just prior to birth in the rat) being equivalent to the

Fig. 5. (A-C) Foxp3 protein assessment in the postnatally developing rat brain. Developmental profile of Foxp3 during the first three postnatal weeks $(\mathrm{PNO}$ : $+=7, \hat{o}=6$; PN7: $q=7, \hat{o}=6$; PN14: i $=7, \hat{\jmath}=6$; PN21: $q=7, \hat{\jmath}=6)$ in the neocortex (A), striatum (B), and hippocampus. All data are expressed as mean ( \pm SEM). Groups with the same symbol are significantly different from each other. A group with more than two alphabetic scripts indicates that the individual group is significantly different from more than one group, e.g. "AB" listing over one group would denote that the group is different from any group with an " $A$ " and is also significantly different from any group with a "B". 

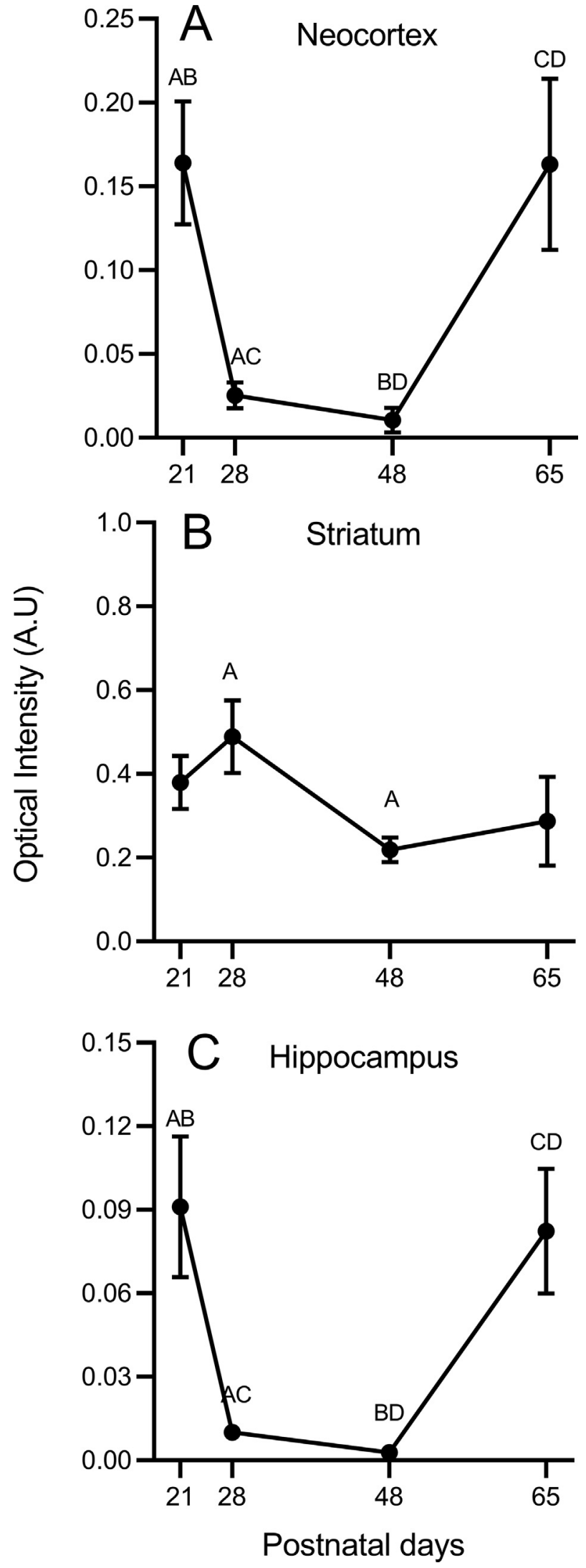

second trimester and PN1- PN10 in the rat being equivalent to the third trimester (West, 1987; Patten et al., 2014). Our results for high expression of Foxp3 during embryonic development support the findings reported for human fetal expression of FOXP3 (Frattini et al., 2012). This suggests Foxp3 may play an important role as a contributor to the development of the brain, especially since the first postnatal week is a critical period for forming neural connections (Bock et al., 2008).

During timepoint 2 (i.e., PN14-21), there is a different pattern of Foxp3 expression, which is brain region specific. For the striatum, but not the neocortex or hippocampus, both mRNA and protein remain unchanged during this period. Furthermore, these levels were decreased compared to timepoint 1 . However, the mRNA and protein levels for the hippocampus increased from timepoint 1, whereas in the neocortex they decreased during this timepoint. This divergent pattern is occurring during a critical transition phase in the animal (Bock et al., 2008). This timepoint (i.e., weaning) is one of the most demanding transitions for the animal behaviorally and cognitively because the animal is less reliant on mother's milk and moving towards solid food (Bateson and Feaver, 1990; Cook, 1999; Bock et al., 2008). Weaning in rats is not caused by a deficit in the dam's ability to produce sufficient milk relative to the nutritional requirements of the developing litter, but is rather induced by changes of the behavioral interactions between the weanlings and the dam (Alberts, 2005; Bock et al., 2008). Subsequently, weanling pups become nutritionally and behaviorally independent from their mother and show marked behavioral transformations (Cramer et al., 1990; Thiels et al., 1990). Therefore, it is not shocking the developmental impact of weaning has such a large influence on the maturation of the brain and behavior (Smith, 1991; Bateson and Kacelnik, 1997; Nakamura et al., 2003; Bock et al., 2008). Thus, we speculate that maintaining a relatively brain region independent expression of Foxp3 may allow the neuroimmune system to remain plastic and responsive for the refinement of the nervous system.

For timepoint 3 (i.e., PN28-PN65), the mRNA for all three brain regions remained relatively stable in their expression. However, the protein levels for Foxp3 in all three brain regions assessed showed a decreasing trend between PN28 and PN48. In contrast, from PN48 to PN65 there was a significant increase in Foxp3

Fig. 6. (A-C) Foxp3 protein measurement in the juvenile and adult rat brain. Developmental profile of Foxp3 after the first three postnatal weeks (PN21: $+=7, \hat{\jmath}=6$; PN28: $ᄋ=7, \hat{\jmath}=7$; PN48: $q=7$, $\hat{o}=6$; PN65: $o=6, \hat{o}=5$ ) in the neocortex $(A)$, striatum $(B)$, and hippocampus (C). All data are expressed as mean ( \pm SEM). Groups with the same symbol are significantly different from each other. A group with more than two alphabetic scripts indicates that the individual group is significantly different from more than one group, e.g. "AB" listing over one group would denote that the group is different from any group with an " $\mathrm{A}$ " and is also significantly different from any group with a "B". 


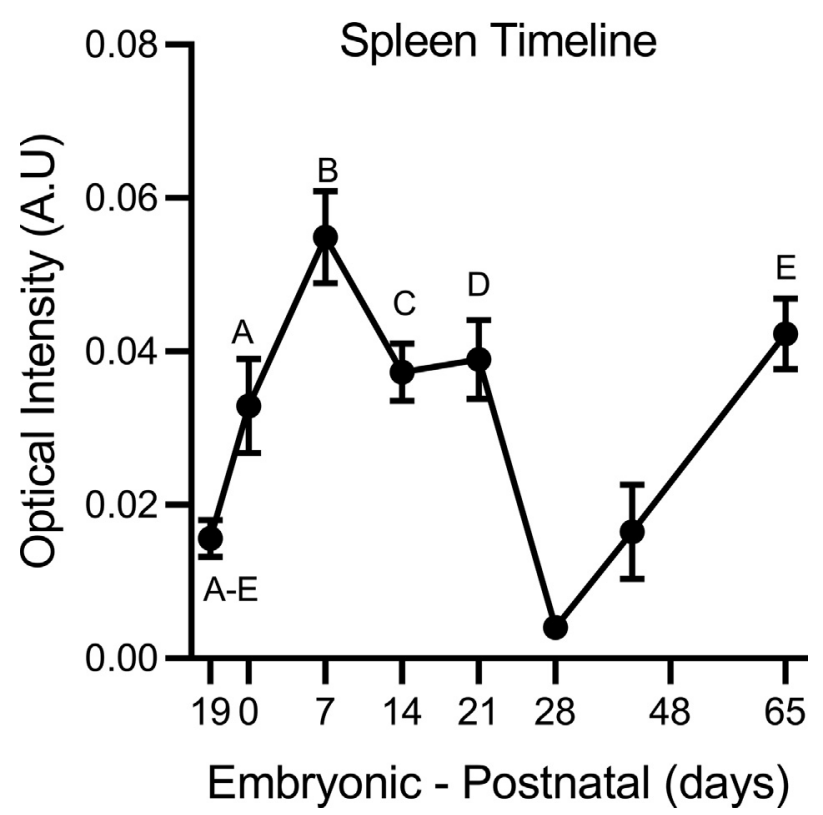

Fig. 7. Foxp3 in the spleen increases over the lifespan from embryonic development into adulthood. Protein values of Foxp3 in the rat spleen across the lifespan $(\mathrm{E} 19: ;=2, \hat{o}=2, \mathrm{PNO}: \stackrel{\circ}{=}=2$, $\hat{\jmath}=2 ;$ PN7: $\uparrow=2, \hat{o}=2 ;$ PN14: $q=2, \hat{o}=2 ;$ PN21: $q=2$, $\hat{\jmath}=2 ; \mathrm{PN} 28:$ 우 $=2, \hat{\jmath}=2 ; \mathrm{PN} 48:$ 우 $=2, \hat{o}=2 ; \mathrm{PN} 65:$ 우 $=2$, $\hat{\delta}=2)$. All data are expressed as mean $( \pm$ SEM). Groups with the same symbol are significantly different from each other. A group with more than two alphabetic scripts indicates that the individual group is significantly different from more than one group, e.g. "AB" listing over one group would denote that the group is different from any group with an " $A$ " and is also significantly different from any group with a "B".

protein for each brain region, except for the striatum. The distinctive pattern between the mRNA and protein is occurring at another critical transition phase in the life of the animal. At this stage, the animal is transitioning from adolescence (i.e., PN28-PN48) into young, adulthood (Evans, 1986; Sengupta, 2013). Pubertal changes (i.e., $\sim$ PN48) have been shown to impact myelination in several areas of the neocortex and contribute to the development of cognitive behaviors in humans and rats (Juraska and Willing, 2017; Darling and Daniel, 2019). Thus, we speculate that Foxp3 may be working to help refine plasticity in the brain during the maturation from adolescence to adulthood. Overall, we propose that the unique expression of Foxp3 across development to be suggestive of this gene's role in contributing to the maturation of the brain across the lifespan. Future research is required to test this idea.

In contrast, we found the spleen, which is rich in Foxp3, showed a different pattern to the one observed in the brain. Foxp3 protein in the spleen showed a steady increase from E19 to PN7, whereas in the brain Foxp3 protein levels were decreasing. Moreover, from PN21 to PN48, Foxp3 protein levels were decreasing in the spleen. This pattern is analogous to the observed trend for the protein levels in the brain. From PN48 to PN65, Foxp3 protein levels steadily increased in the spleen. This is an analogous trend observed in the data from brain tissue. Overall, the early developmental pattern of Foxp3 (i.e., E19-PN14) in the spleen (i.e., periphery) is opposite to what was found in the brain. Therefore, we hypothesize Foxp3 might be playing a dual role in mediating the immune system with one role
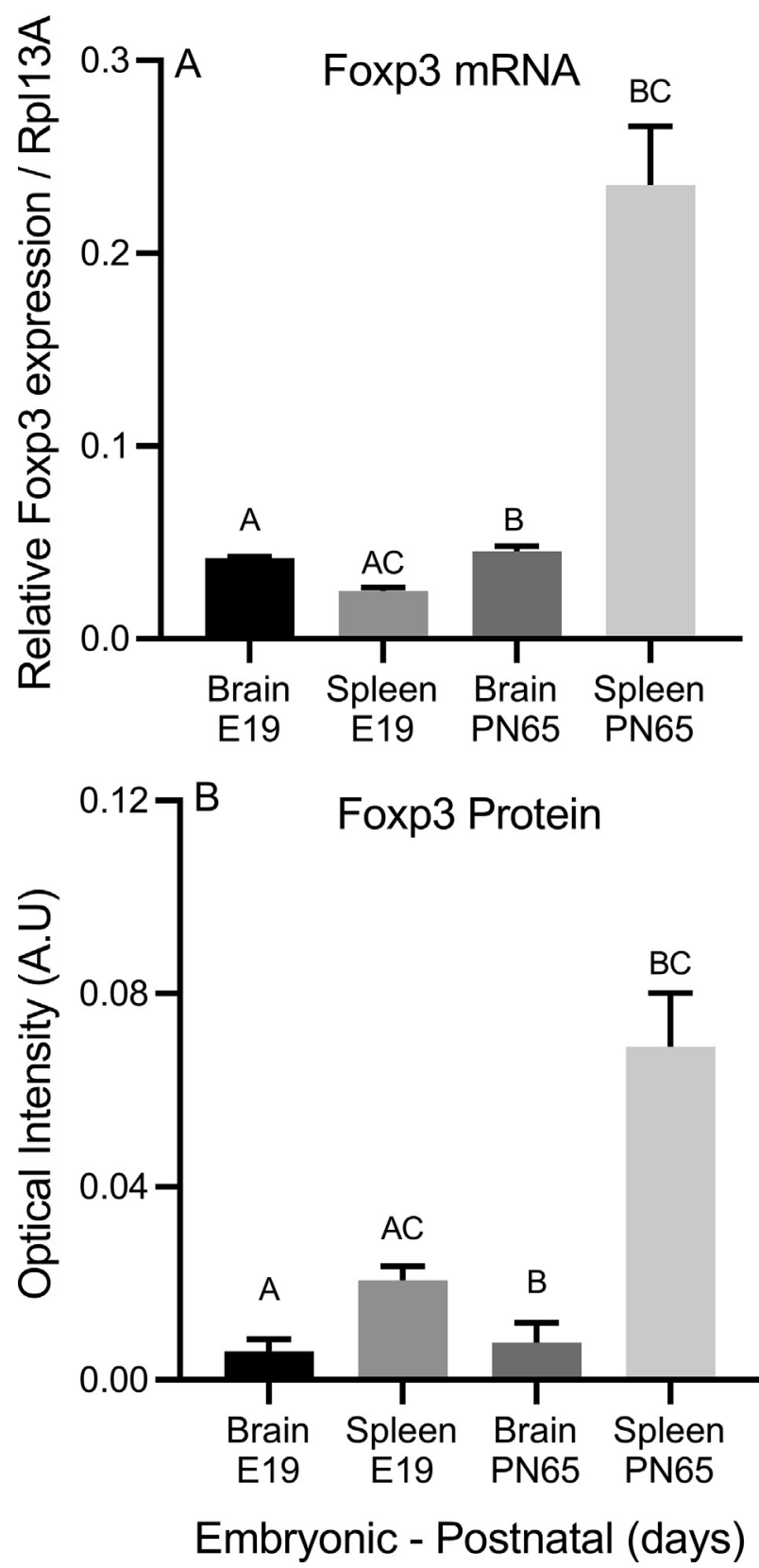

Fig. 8. (A, B) Foxp3 in the spleen increases over the lifespan from embryonic development into adulthood. (A) Foxp3 mRNA in the brain and spleen at embryonic and PN65. For mRNA: (E19-spleen, $n=3$, E19-brain, $n=3$, PN65-spleen, $n=3$, PN65-brain, $n=3$ ). (B) Foxp3 protein levels of in the brain and spleen at embryonic and PN65. For protein: (E19-spleen, $n=4$, E19-brain, $n=5$, PN65spleen, $n=4$, PN65-brain, $n=5$ ). All data are expressed as mean $( \pm$ SEM). Groups with the same symbol are significantly different from each other. A group with more than two alphabetic scripts indicates that the individual group is significantly different from more than one group, e.g. "AB" listing over one group would denote that the group is different from any group with an " $\mathrm{A}$ " and is also significantly different from any group with a "B". 
in the periphery and one in the brain during early development. More research is required to test this hypothesized function.

With respect to sex differences, the same pattern was found for males and females at all timepoints across development. This pattern for Foxp3 diverges from what has been reported for Foxp2 and Foxp1. Both Foxp1 and Foxp2 have been shown to have a sex difference in protein levels during early brain development in both rodents as well as the avians (Teramitsu et al., 2004; Bowers et al., 2013, 2014; Frohlich et al., 2017). The lack of sex differences in Foxp3 suggests that this gene functions similarly in both sexes. We hypothesize that this could be reflective of the fact that Foxp3 is located on the $X$ chromosome, whereas no other member of the Foxp family is located on a sex chromosome (Lu et al., 2017). Moreover, our results are representative of the basal state of the organism. Thus, we would argue that atypical functioning of FOXP3 will negatively impact males more than females, as noted in IPEX (Deng et al., 2012). More research investigating the influence atypical functioning of Foxp3 has on male and females would be beneficial in identifying the etiology for the sex differences in neurodevelopmental disorders.

Our data are the first report of expression for Foxp3 across brain development. In comparison to the other Foxp family, Foxp3 expression is unique. Overall, Foxp1/2/4 have similar expression patterns in the brain that are brain region specific. The noted differences are observed in both humans and rodents where Foxp2 has been shown to have high expression during early embryonic brain development with decreasing expression across the lifespan (Ferland et al., 2003; Campbell et al., 2009; Li et al., 2018). In contrast, Foxp1 in both rodents and humans has been shown have a relatively stable expression across development (Ferland et al., 2003; Li et al., 2018), whereas Foxp4 expression is expressed similarly to Foxp2, but with marked reductions later in life (Takahashi et al., 2008; Li et al., 2018).

As a Foxp subfamily member, it implies Foxp3 has the potential to dimerize with the other Foxp members and form heterodimers in the brain as noted to occur between the other Foxp family members (Li et al., 2004; Mendoza et al., 2015; Mendoza and Scharff, 2017). A likely candidate is Foxp1 because this Foxp family member gene is known to play a role in immune cell function by its repression of immune regulatory genes in the brain (Tang et al., 2012). In the PNS, FOXP1 has also been found to associate with FOXP3 and it is thought that both transcription factors promote each other's binding with downregulation of FOXP1 resulting in a marked decrease in FOXP3 binding (Konopacki et al., 2019). Future experiments currently underway are testing the potential interactions between Foxp3 and the other Foxp family members in the brain. Interestingly, a recent publication has shown Foxp3 to be expressed by microglia (Chung et al., 2010; Yi et al., 2016). Microglia have been shown to be a contributor to the modification of not only brain development but also behavior (Lenz et al., 2013). No publication to our knowledge has investigated Foxp3's impact on microglia and how they may work together to sculpt the neural circuits responsible for developing the dendritic morphology and spine growth of neurons, as well as behavior. This could be an additional unique feature of Foxp3 in the brain given its cell type expression in the brain may not be on neurons, as observed with Foxp 1/2/4 (Tam et al., 2011; Bowers et al., 2014). Future investigations testing the cell type expression of Foxp3 in the brain are clearly warranted.

\section{ACKNOWLEDGMENTS}

We would like to thank the following people: Mark Bohler, G., Franklin Edwards, and Miguel Perez. Mark and Franklin helped with the early collection of tissue and processing. Miguel helped by contributing writing comments to early drafts of the manuscript.

\section{FUNDING}

This work was supported by the National Institutes of Health [grant R00 MH101252] and the Virginia Techn OASF to JMB.

\section{REFERENCES}

Alberts JR (2005) Infancy. In: Whishaw IQ, Kolb B, editors. The behavior of the laboratory rat. New York: Oxford University Press. p. 266-277.

Allan SE, Passerini L, Bacchetta R, Crellin N, Dai M, Orban PC, Ziegler SF, Roncarolo MG, et al. (2005) The role of 2 FOXP3 isoforms in the generation of human CD4 + Tregs. J Clin Invest 115:3276-3284.

Bacon C, Rappold GA (2012) The distinct and overlapping phenotypic spectra of FOXP1 and FOXP2 in cognitive disorders. Hum Genet 131:1687-1698.

Bateson M, Kacelnik A (1997) Starlings' preferences for predictable and unpredictable delays to food. Anim Behav 53:1129-1142.

Bateson PMM, Feaver J (1990) Play in the domestic cat is enhanced by rationing of the mother during lactation. Anim Behav 40:514-525.

Bauman MD, losif AM, Ashwood P, Braunschweig D, Lee A, Schumann CM, Van de Water J, Amaral DG (2013) Maternal antibodies from mothers of children with autism alter brain growth and social behavior development in the rhesus monkey. Transl Psychiatry 3 e278.

Benros ME, Mortensen PB (2019) Role of infection, autoimmunity, atopic disorders, and the immune system in schizophrenia: evidence from epidemiological and genetic studies. Curr Top Behav Neurosci.

Bock J, Murmu RP, Ferdman N, Leshem M, Braun K (2008) Refinement of dendritic and synaptic networks in the rodent anterior cingulate and orbitofrontal cortex: critical impact of early and late social experience. Dev Neurobiol 68:685-695.

Bowers JM, Konopka G (2012) The role of the FOXP family of transcription factors in ASD. Dis Markers 33:251-260.

Bowers JM, Perez-Pouchoulen M, Edwards NS, McCarthy MM (2013) Foxp2 mediates sex differences in ultrasonic vocalization by rat pups and directs order of maternal retrieval. J Neurosci 33:3276-3283

Bowers JM, Perez-Pouchoulen M, Roby CR, Ryan TE, McCarthy MM (2014) Androgen modulation of Foxp1 and Foxp2 in the developing rat brain: impact on sex specific vocalization. Endocrinology 155:4881-4894.

Brimberg L, Mader S, Jeganathan V, Berlin R, Coleman TR, Gregersen PK, Huerta PT, Volpe BT, et al. (2016) Caspr2reactive antibody cloned from a mother of an ASD child mediates an ASD-like phenotype in mice. Mol Psychiatry 21:1663-1671. 
Brunkow ME, Jeffery EW, Hjerrild KA, Paeper B, Clark LB, Yasayko SA, Wilkinson JE, Galas D, et al. (2001) Disruption of a new forkhead/winged-helix protein, scurfin, results in the fatal lymphoproliferative disorder of the scurfy mouse. Nat Genet 27:68-73.

Campbell P, Reep RL, Stoll ML, Ophir AG, Phelps SM (2009) Conservation and diversity of Foxp2 expression in muroid rodents: functional implications. J Comp Neurol 512:84-100.

Chung HS, Lee JH, Kim H, Lee HJ, Kim SH, Kwon HK, Im SH, Bae H (2010) Foxp3 is a novel repressor of microglia activation. Glia 58:1247-1256

Cook CJ (1999) Patterns of weaning and adult response to stress. Physiol Behav 67:803-808.

Cramer CP, Thiels E, Alberts JR (1990) Weaning in rats: I. Maternal behavior. Dev Psychobiol 23:479-493.

Dallaire MJ, Ferland C, Page N, Lavigne S, Davoine F, Laviolette M (2003) Endothelial cells modulate eosinophil surface markers and mediator release. Eur Respir J 21:918-924.

Darling JS, Daniel JM (2019) Pubertal hormones mediate sex differences in levels of myelin basic protein in the orbitofrontal cortex of adult rats. Neuroscience 406:487-495.

Deng G, Xiao Y, Zhou Z, Nagai Y, Zhang H, Li B, Greene MI (2012) Molecular and biological role of the FOXP3 N-terminal domain in immune regulation by $\mathrm{T}$ regulatory/suppressor cells. Exp Mol Pathol 93:334-338.

Du J, Huang C, Zhou B, Ziegler SF (2008) Isoform-specific inhibition of ROR alpha-mediated transcriptional activation by human FOXP3. J Immunol 180:4785-4792.

Smith ES (1991) The influence of nutrition and postpartum mating on weaning and subsequent play behavior of hooded rats. Anim Behav 41:513-524.

Eufrasio de Figueiredo WM, Heredia FF, Santos AS, da Rocha Braga R, Marciano Fonseca FR, de Castro Lucia, Rodrigues N, Abreu TM, de Lima Maria, Pompeu M, et al. (2019) CXCL10 treatment promotes reduction of IL-10 $(+)$ regulatory $\mathrm{T}(\mathrm{Foxp} 3(+)$ and $\mathrm{Tr} 1)$ cells in the spleen of BALB/c mice infected by Leishmania infantum. Exp Parasitol 207107789.

Evans AM (1986) Age at puberty and first litter size in early and late paired rats. Biol Reprod 34:322-326.

Ferland RJ, Cherry TJ, Preware PO, Morrisey EE, Walsh CA (2003) Characterization of Foxp2 and Foxp1 mRNA and protein in the developing and mature brain. J Comp Neurol 460:266-279.

Fong WL, Kuo HY, Wu HL, Chen SY, Liu FC (2018) Differential and overlapping pattern of Foxp1 and Foxp2 expression in the striatum of adult mouse brain. Neuroscience 388:214-223.

Fontenot JD, Gavin MA, Rudensky AY (2003) Foxp3 programs the development and function of CD $4+\mathrm{CD} 25+$ regulatory $T$ cells. Nat Immunol 4:330-336.

Fontenot JD, Rasmussen JP, Williams LM, Dooley JL, Farr AG, Rudensky AY (2005) Regulatory T cell lineage specification by the forkhead transcription factor foxp3. Immunity 22:329-341.

Frattini V, Pisati F, Speranza MC, Poliani PL, Frige G, Cantini G, Kapetis D, Cominelli M, et al. (2012) FOXP3, a novel glioblastoma oncosuppressor, affects proliferation and migration. Oncotarget 3:1146-1157.

Frohlich H, Rafiullah R, Schmitt N, Abele S, Rappold GA (2017) Foxp1 expression is essential for sex-specific murine neonatal ultrasonic vocalization. Hum Mol Genet 26:1511-1521.

Fu R, Jiang Y, Zhou J, Zhang J (2019) Rebamipide ophthalmic solution modulates the ratio of $\mathrm{T}$ helper cell 17/regulatory $\mathrm{T}$ cells in dry eye disease mice. Mol Med Rep 19:4011-4018.

Girirajan S, Brkanac Z, Coe BP, Baker C, Vives L, Vu TH, Shafer N, Bernier R, et al. (2011) Relative burden of large CNVs on a range of neurodevelopmental phenotypes. PLoS Genet 7 e1002334.

Gottfried C, Bambini-Junior V (2018) Insights into the relationship of the immune system with neurodevelopmental and psychiatric disorders. NeurolmmunoModulation 25:243-245.

Greenough WT, Black JE, Wallace CS (1987) Experience and brain development. Child Dev 58:539-559.
Haque R, Lei F, Xiong X, Song J (2011) The regulation of FoxP3expressing regulatory $T$ cells. Endocr Metab Immune Disord Drug Targets 11:334-346.

Hori S, Nomura T, Sakaguchi S (2003) Control of regulatory T cell development by the transcription factor Foxp3. Science 299:1057-1061.

Juraska JM, Willing J (2017) Pubertal onset as a critical transition for neural development and cognition. Brain Res 1654:87-94.

Kaestner KH, Knochel W, Martinez DE (2000) Unified nomenclature for the winged helix/forkhead transcription factors. Genes Dev 14:142-146.

Khandaker GM, Pearson RM, Zammit S, Lewis G, Jones PB (2014) Association of serum interleukin 6 and C-reactive protein in childhood with depression and psychosis in young adult life: a population-based longitudinal study. JAMA Psychiatry 71:1121-1128.

Kohane IS, McMurry A, Weber G, MacFadden D, Rappaport L, Kunkel L, Bickel J, Wattanasin N, et al. (2012) The co-morbidity burden of children and young adults with autism spectrum disorders. PLoS ONE 7 e33224.

Konopacki C, Pritykin Y, Rubtsov Y, Leslie CS, Rudensky AY (2019) Transcription factor Foxp1 regulates Foxp3 chromatin binding and coordinates regulatory T cell function. Nat Immunol 20:232-242.

Lai CS, Fisher SE, Hurst JA, Vargha-Khadem F, Monaco AP (2001) A forkhead-domain gene is mutated in a severe speech and language disorder. Nature 413:519-523.

Lenz KM, Nugent BM, Haliyur R, McCarthy MM (2013) Microglia are essential to masculinization of brain and behavior. J Neurosci 33:2761-2772.

Levene H (1960) Robust tests of equality of variances. Stanford, CA: Stanford University Press.

Li M, Santpere G, Imamura Kawasawa Y, Evgrafov OV, Gulden FO, Pochareddy S, Sunkin SM, Li Z, et al. (2018) Integrative functional genomic analysis of human brain development and neuropsychiatric risks. Science 362.

Li S, Weidenfeld J, Morrisey EE (2004) Transcriptional and DNA binding activity of the Foxp $1 / 2 / 4$ family is modulated by heterotypic and homotypic protein interactions. Mol Cell Biol 24:809-822.

Lord C, Risi S, DiLavore PS, Shulman C, Thurm A, Pickles A (2006) Autism from 2 to 9 years of age. Arch Gen Psychiatry 63:694-701.

Lu L, Barbi J, Pan F (2017) The regulation of immune tolerance by FOXP3. Nat Rev Immunol 17:703-717.

Lu MM, Li S, Yang H, Morrisey EE (2002) Foxp4: a novel member of the Foxp subfamily of winged-helix genes co-expressed with Foxp1 and Foxp2 in pulmonary and gut tissues. Mech Dev 119 (Suppl 1):S197-S202.

Mailer RKW (2018) Alternative splicing of FOXP3-virtue and vice. Front Immunol 9:530.

McGee A, Li G, Lu Z, Qiu S (2014) Convergent synaptic and circuit substrates underlying autism genetic risks. Front Biol (Beijing) 9:137-150.

Mendoza E, Scharff C (2017) Protein-protein interaction among the FoxP family members and their regulation of two target genes, VLDLR and CNTNAP2 in the zebra finch song system. Front Mol Neurosci 10:112.

Mendoza E, Tokarev K, During DN, Retamosa EC, Weiss M, Arpenik N, Scharff C (2015) Differential coexpression of FoxP1, FoxP2, and FoxP4 in the Zebra Finch (Taeniopygia guttata) song system. J Comp Neurol 523:1318-1340.

Nakamura K, Kikusui T, Takeuchi Y, Mori Y (2003) The influence of early weaning on aggressive behavior in mice. J Vet Med Sci 65:1347-1349.

Ohkura N, Kitagawa Y, Sakaguchi S (2013) Development and maintenance of regulatory T cells. Immunity 38:414-423.

Patten AR, Fontaine CJ, Christie BR (2014) A comparison of the different animal models of fetal alcohol spectrum disorders and their use in studying complex behaviors. Front Pediatr 2:93. 
Patterson PH (2009) Immune involvement in schizophrenia and autism: etiology, pathology and animal models. Behav Brain Res 204:313-321.

Rainville JR, Tsyglakova M, Hodes GE (2018) Deciphering sex differences in the immune system and depression. Front Neuroendocrinol 50:67-90.

Rakic P, Bourgeois JP, Eckenhoff MF, Zecevic N, Goldman-Rakic PS (1986) Concurrent overproduction of synapses in diverse regions of the primate cerebral cortex. Science 232:232-235.

Rappold GA, Bacon C, Schneider M, Le Magueresse C, Frohlich H, Sticht C, Gluch C, Monyer H (2017) Brain-specific foxp1 deletion impairs neuronal development and causes autistic-like behaviour. Eur Neuropsychopharmacol 27:S421.

Raven F, Van der Zee EA, Meerlo P, Havekes R (2018) The role of sleep in regulating structural plasticity and synaptic strength: Implications for memory and cognitive function. Sleep Med Rev 39:3-11.

Rossi CC, Fuentes J, Van de Water J, Amaral DG (2013) Brief report: antibodies reacting to brain tissue in Basque Spanish children with autism spectrum disorder and their mothers. J Autism Dev Disord.

Sengupta P (2013) The laboratory rat: relating its age with human's. Int J Prev Med 4:624-630.

Shu L, Xu CQ, Yan ZY, Yan Y, Jiang SZ, Wang YR (2019) Poststroke microglia induce sirtuin2 expression to suppress the antiinflammatory function of infiltrating regulatory $T$ cells. Inflammation 42:1968-1979.

Sin C, Li H, Crawford DA (2015) Transcriptional regulation by FOXP1, FOXP2, and FOXP4 dimerization. J Mol Neurosci 55:437-448.

Takahashi H, Takahashi K, Liu FC (2009) FOXP genes, neural development, speech and language disorders. Adv Exp Med Biol 665:117-129.

Takahashi K, Liu FC, Hirokawa K, Takahashi H (2008) Expression of Foxp4 in the developing and adult rat forebrain. J Neurosci Res 86:3106-3116

Tam WY, Leung CK, Tong KK, Kwan KM (2011) Foxp4 is essential in maintenance of Purkinje cell dendritic arborization in the mouse cerebellum. Neuroscience 172:562-571.

Tang B, Becanovic K, Desplats PA, Spencer B, Hill AM, Connolly C, Masliah E, Leavitt BR, et al. (2012) Forkhead box protein p1 is a transcriptional repressor of immune signaling in the CNS: implications for transcriptional dysregulation in Huntington disease. Hum Mol Genet 21:3097-3111.

Teramitsu I, Kudo LC, London SE, Geschwind DH, White SA (2004) Parallel FoxP1 and FoxP2 expression in songbird and human brain predicts functional interaction. J Neurosci 24:3152-3163.

Thiels E, Alberts JR, Cramer CP (1990) Weaning in rats: II. Pup behavior patterns. Dev Psychobiol 23:495-510.

Turner ME, Martin C, Martins AS, Dunmire J, Farkas J, Ely DL, Milsted A (2007) Genomic and expression analysis of multiple Sry loci from a single Rattus norvegicus $Y$ chromosome. BMC Genet 8:11.

Vanleeuwen JE, Penzes P (2012) Long-term perturbation of spine plasticity results in distinct impairments of cognitive function. $J$ Neurochem 123:781-789.

Vernes SC, Newbury DF, Abrahams BS, Winchester L, Nicod J, Groszer M, Alarcon M, Oliver PL, et al. (2008) A functional genetic link between distinct developmental language disorders. N Engl J Med 359:2337-2345.

Walecki M, Eisel F, Klug J, Baal N, Paradowska-Dogan A, Wahle E, Hackstein H, Meinhardt A, et al. (2015) Androgen receptor modulates Foxp3 expression in CD4+CD25+Foxp3 + regulatory T-cells. Mol Biol Cell 26:2845-2857.

Walker MR, Kasprowicz DJ, Gersuk VH, Benard A, Van Landeghen M, Buckner JH, Ziegler SF (2003) Induction of FoxP3 and acquisition of $\mathrm{T}$ regulatory activity by stimulated human CD4 + CD25- T cells. J Clin Invest 112:1437-1443.

West JR (1987) Fetal alcohol-induced brain damage and the problem of determining temporal vulnerability: a review. Alcohol Drug Res $7: 423-441$.

Yi MH, Zhang E, Kim JJ, Baek H, Shin N, Kim S, Kim SR, Kim HR, et al. (2016) CD200R/Foxp3-mediated signalling regulates microglial activation. Sci Rep 6:34901.

Zamudio-Bulcock PA, Morton RA, Valenzuela CF (2014) Third trimester-equivalent ethanol exposure does not alter complex spikes and climbing fiber long-term depression in cerebellar Purkinje neurons from juvenile rats. Alcohol Clin Exp Res 38:1293-1300.

Zhao D, Mokhtari R, Pedrosa E, Birnbaum R, Zheng D, Lachman HM (2017) Transcriptome analysis of microglia in a mouse model of Rett syndrome: differential expression of genes associated with microglia/macrophage activation and cellular stress. Mol Autism 8:17.

(Received 10 October 2019, Accepted 20 June 2020)

(Available online 27 June 2020) 